\title{
Determination of Moisture Sorption Isotherm of Crosslinked Millet Flour and Oxirane Using GAB and BET
}

\author{
M. S. Alamri, A. A. Mohamed (D), S. Hussain, M. A. Ibraheem, and Akram A. Abdo Qasem \\ Department of Food Science and Nutrition, King Saud University, Riyadh, Saudi Arabia \\ Correspondence should be addressed to A. A. Mohamed; abdmohamed@ksu.edu.sa
}

Received 25 September 2018; Revised 19 November 2018; Accepted 21 November 2018; Published 11 December 2018

Academic Editor: Carola Esposito Corcione

Copyright (C) 2018 M. S. Alamri et al. This is an open access article distributed under the Creative Commons Attribution License, which permits unrestricted use, distribution, and reproduction in any medium, provided the original work is properly cited.

\begin{abstract}
Epoxy resin was prepared by crosslinking epoxidized oil and millet flour. The reaction was carried out at three different temperatures $\left(25,40\right.$, and $\left.55^{\circ} \mathrm{C}\right)$ and zinc chloride levels $(1,2$, and $3 \%)$. Moisture sorption isotherms were determined at 0.1 to 0.9 water activity $\left(a_{\mathrm{w}}\right)$ using a gravimetric sorption analyzer (Q 2000). The sigmoidal shape (type II) of the resin isotherms exhibited lower equilibrium moisture content (EMC) at higher temperature. The experimental data were modeled using GAB (Guggenheim-Anderson-de Boer) and BET (Brunauer-Emmett-Teller). The EMC of the resin was significantly lower than that of the flour, which could be attributed to the decrease in the number of water-binding sites due to the creation of dense areas during crosslinking. The low root-mean-square error (RMSE) indicates that GAB and BET were suitable for predicting the water sorption isotherm for millet flour resin. The heat of sorption of the resin was large at low moisture content and increased at higher relative humidity. It is recommended that millet flour resin be used at relative humidity below $60 \%$.
\end{abstract}

\section{Introduction}

Petroleum-based materials, widely used, have many advantages such as gas and moisture permeability control and are resilient. Nonetheless, these materials pose a global threat of environmental pollution because of disposal difficulties due to the heat and exhaust generated when burned. Consequently, consumer demands and rising petroleum prices inspired the development of alternative renewable resources originating from agricultural sources. Renewable materials can be classified into three groups: extracted directly from agricultural raw materials (e.g., protein, starch, or lipids); produced by microorganisms (e.g., polyhydroxy-alcanoates, poly-3hydroxybutyrate); and synthesized from bio-derived monomers (such as polylactic acid) [1-3]. In spite of the widespread research, thermoplastic plant-based materials are lacking the properties of synthetic plastic materials [1]. Plant-based materials suffer two major drawbacks, water stability and brittleness. Agriculturalbased raw materials are difficult to process because of insolubility in common solvent and of lack of durability [2]. This can be resolved by a combination of chemical modification and specialized processes.

The relationship between water activity, moisture content, and temperature is called the moisture sorption isotherm which is usually a complex and unique process due to the different ways of interaction between water and the solid components of the material at different moisture content. The adsorption of water into the structure of a polymer can impact its structure by reducing the strength and affecting the thermomechanical properties. Therefore, the effect of moisture on epoxy network and its properties were studied [3-6]. Studies show that water absorption can disrupt hydrogen bonds among segments of the polymers and cause swelling and increase in diffusion coefficient of water within the polymer. Permanent damage to the polymer can occur if water breaks linkage between segments of the polymer. Generally, water desorption studies are recommended to ascertain how water absorption affects epoxy resins [7-18]. Epoxy-resin degradation caused by water adsorption occurs by formation of hydrogen bonds between the water 
molecules and polar groups present in the polymer chain, causing rupture of the initial network [19]. Water absorption can cause plasticization of the resin, but it can also cause changes in the stress state, which favors the formation of cracks due to swelling. These occurrences can cause variation in the internal structure of the material which can bring about weight gain [19].

Adamson postulated that adsorption of moisture below $\mathrm{Tg}$ is a three-stage process in which the absorbed moisture first occupies the free volume present in the form of vacuums [20]. In the second stage, water becomes bound to network sites instigating resin swelling. Finally, water enters the densely crosslinked regions. The free volume is defined here as the difference between the measured volume of a polymer and the occupied volume. This difference is the result of "holes" or "voids" caused by packing during crosslinking.

Abdelkader and White explicitly examined the effects of heat treatment on the water/resin interactions and concluded that resins prepared at different temperature absorbed about the same amount of water, and the water diffusion coefficient derived from two sets of absorption measurements was about the same [21]. Mohamed et al. reported that the solubility of epoxy resin prepared from epoxidized sunflower oil and catalyzed by zinc chloride was the most stable than other oils in both acidic and alkaline environments because it maintained minimal variation in weight gain through $72 \mathrm{~h}$ [22]. The most weight was gained by epoxidized cottonseed oil resin. Epoxidized sunflower oil resin gained the least weight when immersed in $1.0 \mathrm{M} \mathrm{HCl}$ indicating stability of the resin which can be attributed to the presence of more epoxy rings leading to more crosslinking sites [20].

The modifications of epoxy resin induced by temperature and/or moisture are directly linked to the presence of unreacted sites during the gelation and setting of the resin. Moisture absorption, in particular, could also promote undesirable dimensional changes on the final epoxy resin product. It has been established that even for a completely cured epoxy resin, many hydrophilic sites could be available on the final network of the resin. Actually, for the epoxy system, the cure reaction circumstances are driven by the primary amino addition reaction $\left(-\mathrm{NH}_{2}\right)$ and the oxirane group, generating hydrophilic hydroxyl groups $(-\mathrm{OH})$ [23]. For nonstoichiometric formulations with excess of epoxy monomer, the epoxy rings could, in principle, react with these hydroxyl groups, but this secondary reaction will not contribute to the reduction of the number of hydrophilic $\mathrm{OH}$ groups [24, 25]. In addition, amines are also strong hydrophilic groups and when in excess could contribute to moisture uptake and to resin plasticization and swelling [26].

It was not possible to correlate water absorption behavior to the developed macromolecular structure when the epoxy/hardener ratio was varied. Obviously, epoxy/hardener ratios bring about a two-phase macromolecular structure composed of regions with high crosslinking (dense regions) and lower crosslinking. Epoxy-rich systems have a more open macromolecular structure with a lower dense-phase fraction than aminerich systems, which present a more compact two-phase structure [27].

The GAB (Guggenheim-Anderson-de Boer) and BET (Brunauer-Emmett-Teller) are the most common models used for the determination of the sorption isotherms for different materials. The GAB model is represented by constant $\mathrm{C}$ and $\mathrm{K}$. Constant $\mathrm{C}$ is a positive value that represents the total heat of the first layer of sorption. Due to the strong exothermic interaction of water vapor with the primary sorption sites of the material, $\mathrm{C}$ value has to take a positive value. The $\mathrm{K}$ constant symbolizes the properties of the multilayer molecules (bulk liquid). Negative $\mathrm{C}$ is physically impossible, whereas $\mathrm{K}$ values higher than unity are irrational. It is well established that the validity of a sorption model cannot be proved just by fitting the experimental data, but a physicochemical explanation is also required [28]. In some cases, the $R^{2}$ of the GAB model can be $>0.90$, but the model may not fit the data. Sorption data can be gathered at different temperatures, which permits the determination of the heat of sorption at various moisture contents using the best-fitting equation [29].

The objectives of this work were to present data on the absorption of water by cured epoxy resin prepared by amidolysis of oxirane of epoxidized sesame and cottonseed oil catalyzed by zinc chloride. Other variables investigated were the level of zinc chloride and temperature. The experimental data will be applied to the BET and GAB isotherm models. From the temperature dependence of the sorption isotherms, the isosteric heat of sorption was calculated.

\section{Materials and Methods}

2.1. Materials. Millet flour, sesame oil, and cottonseed oil were purchased from the local market.

Epoxy resin was developed using epoxidized sesame oil or cottonseed oil and millet flour (1.5\% oil, $13.3 \%$ proteins, and $84 \%$ carbohydrates).

2.2. Development of Epoxidized Oils. The epoxy resin was developed by reacting sesame or cottonseed oil with hydrogen peroxide in the presence of formic acid. The oil of interest (about $280 \mathrm{~g}$ ) was placed in a three-neck flask with a heating jacket connected to circulating water bath. On the top of the flask, a mechanical stirrer with variable speed was placed to maintain good mixing and stabilize the temperature during the reaction, where the initial temperature was $40^{\circ} \mathrm{C}$ [30]. After adding $25 \mathrm{ml}$ formic acid and initiating the stirrer, $200 \mathrm{ml}$ of $50 \%$ peroxide was added, and the reactor temperature was set at $70^{\circ} \mathrm{C}$. After 7-9 hours of reaction time, the product was washed with saturated ethyl acetate and $\mathrm{NaCl}$ at $\mathrm{pH}$ adjusted to 7.5 and dried at $60^{\circ} \mathrm{C}$ in a vacuum oven.

2.3. Analysis of Epoxidized Oils. The yield of the reaction was tested by the Fourier transform infrared (FTIR) attenuated total reflection (ATR) method. Bands at $824-842 \mathrm{~cm}^{-1}$ of the C-O-C stretching of the epoxy ring were detected by the FTIR 
[31]. The end of the reaction was determined by observing the size of the oxirane peak and amide (I and II) band as well.

2.4. Development of Epoxy Resin. The epoxy resin preparation started by adding epoxidized oil $(50 \mathrm{~g})$ in a jacketed glass reactor with three openings. The reaction was carried out at $70^{\circ} \mathrm{C}$ and three levels of zinc chloride $\left(1,2\right.$, or $3 \%$ of $\mathrm{ZnCl}_{2}$ ). The flour (20 g millet) was added slowly at $650 \mathrm{rpm}$ for few minutes and then at $550 \mathrm{rpm}$ until the reaction is completed. A little nitrogen purge was applied during the reaction. The end of the reaction was determined by observing the product thickness, disappearance of the $\mathrm{C}-\mathrm{O}-\mathrm{C}$ bonds, and reduction on amide I and II bands. The end of the reaction was denoted when the material became thick enough to prevent the stirrer from turning, in addition, to the disappearance of the C-O-C band at $845-824 \mathrm{~cm}^{-1}$ as mentioned earlier. The reduction in amide I at $1655 \mathrm{~cm}^{-1}$ and II at $1533 \mathrm{~cm}^{-1}$ on the IR spectrum was also another indicator of the reaction completion.

2.5. Sorption Isotherms Determination. Epoxy resin moisture sorption isotherms were determined gravimetrically using a sorption analyser Q5000 SA (TA instruments, New Castile, DE 19720). Samples (10 mg) were loaded using quartz pans, and the relative humidity was automatically set between 10 and $90 \%\left(0.1-0.9 a_{\mathrm{w}}\right)$ at $25^{\circ} \mathrm{C}, 40^{\circ} \mathrm{C}$, and $55^{\circ} \mathrm{C}$. The instrument provided the equilibrium moisture content (EMC) directly after each step. The EMC will be used for determining the GAB and BET parameters.

2.6. Sorption Isotherm Models. In order to determine the best fit corresponding to $a_{\mathrm{w}}$ at the selected temperature, GAB and BET models were applied.

The GAB model is represented using the following relationship:

$$
m=\frac{C K a_{\mathrm{w}} m_{o}}{\left(1-k a_{\mathrm{w}}\right)\left(1-k a_{\mathrm{w}}+C K a_{\mathrm{w}}\right)},
$$

where $a_{\mathrm{w}}$ is the water activity, $m_{o}$ is the monolayer moisture content, and $C$ and $K$ represent the GAB constants derived from the following polynomial equation:

$$
\frac{a_{\mathrm{w}}}{\mathrm{EMC}}=\alpha\left(a_{\mathrm{w}}\right)^{2}+\beta+Y
$$

where $a_{\mathrm{w}}$ is the water activity and EMC is the equilibrium moisture content. The terms $\alpha, \beta$, and $\gamma$ can be calculated by nonlinear regression of the experimental EMC as a function of $a_{\mathrm{w}}$. Therefore, the $C$ and $K$ values can be obtained as follows:

$$
\begin{aligned}
& \alpha=\frac{k}{m_{o}}\left[\frac{1}{C}-1\right], \\
& \beta=\frac{1}{m_{o}}\left[1-\frac{2}{C}\right], \\
& \gamma=\frac{1}{m_{o} C K},
\end{aligned}
$$

where

$$
\begin{aligned}
C & =\frac{T+\sqrt{T^{2}-4 T}}{2}, \\
T & =\frac{\beta^{2}}{-\alpha \gamma}+4, \\
K & =\frac{1}{C m_{o} \gamma}, \\
m_{o} & =\left[1-\frac{2}{C}\right] \times \frac{1}{\beta} .
\end{aligned}
$$

Therefore, EMC can be estimated by rearranging Equation (1):

$$
\frac{m_{\mathrm{o}}}{\mathrm{EMC}}=\frac{\left[1-a_{\mathrm{w}}\right][1+(C-1)] a_{\mathrm{w}}}{C K a_{\mathrm{w}}},
$$

where $m_{\mathrm{o}}$ is the monolayer moisture content and EMC is the equilibrium moisture content.

The BET model is symbolized using the following equation:

$$
m=\frac{C a_{\mathrm{w}} m_{\mathrm{o}}}{\left(1-a_{\mathrm{w}}\right)[1+(C-1)] a_{\mathrm{w}}} .
$$
form:

After arrangement, the BET equation takes the following

$$
\frac{m_{\mathrm{o}}}{\mathrm{EMC}}=\frac{\left[1-a_{\mathrm{w}}\right][1+(c-1)]}{C a_{\mathrm{w}}} .
$$

2.7. Model Validation. The GAB and BET models were fitted using nonlinear regression. All calculations were made using SigmaPlot version 10.0 . Besides the $R^{2}$ of the nonlinear regression, the goodness of the model fit was tested using the percentage root-mean-square error, RMSE (Kaya and Kahyaoglu 2005) [32]:

$$
\mathrm{RMSE}=\sqrt{\frac{\sum_{i=1}^{N}\left(m_{\mathrm{e}}^{i}-m_{\mathrm{p}}^{i}\right)}{N}},
$$

where $m_{\mathrm{e}}$ is the experimental EMC value, $m_{\mathrm{p}}$ is the predicted value, and $N$ is the number of experimental data.

2.8. Determination of Isosteric Heat of Sorption (IHS). The IHS can be calculated using Clauausius-Clapeyron Equation (9) (Kaymak-Ertekin and Gedik) [33]. The calculated IHS is a measure of the magnitude of the binding energy which reflects the availability of polar sites for binding water vapor during sorption:

$$
q_{\mathrm{st}}=-R \frac{\operatorname{Ln} a_{\mathrm{w}}}{1 / T}
$$


where $q_{\mathrm{is}}=$ isosteric heat of sorption $(\mathrm{kJ} / \mathrm{mol} \cdot \mathrm{K}) ; R=$ universal gas constant which is $8.314 \mathrm{~kJ} / \mathrm{mol} \cdot \mathrm{K} ; a_{\mathrm{w}}$ water activity; and $T=$ temperature in kelvin. Plot of $\ln a_{\mathrm{w}}$ vs. $1 / T$ and the slope is equal to $q_{\mathrm{st}} / R$; therefore, $q_{\text {is }}=-R *$ slope.

\section{Results and Discussion}

3.1. Characteristics of the Moisture Sorption Isotherms. The experimental moisture sorption isotherm data for millet flour (MF) were obtained at 25,40 , and $55^{\circ} \mathrm{C}$ and water activity range from 0.1 to 0.9 (Figure 1) which exhibited sigmoidal shape (type II isotherm) [34]. The increase in temperature from $25^{\circ} \mathrm{C}$ to $55^{\circ} \mathrm{C}$ instigated lower equilibrium moisture content (EMC) at higher water activity. The reason for that was the higher water vapor pressure in the millet flour which accelerated the transfer of moisture from the samples to the surrounding air. This indicates dynamic equilibrium changes between water vapor and the absorbing surface of the material due to higher temperature. This occurrence is observed for most materials rich in hydroxyl groups such as starch or any other polar groups located on the surface. Therefore, higher temperature can increase water activity at the same EMC which is the main reason for increase in microbial and enzymatic activity [35]. The EMC of millet epoxy-resin decreased significantly compared to the flour (Figure 2). This could be attributed to the decrease in the number of water-binding sites and the development of dense areas due to crosslinking. Despite the increase in the zinc chloride level, the EMC remained about the same (Figure 2). Cured crosslinked epoxy resin consists of a twophase system. In addition, the network structure of the crosslinked resin is not really homogeneous, but it is a mixture of highly crosslinked regions (dense) entrenched in less crosslinked region. Because of the dense structure, highly crosslinked regions are less likely to be penetrated by water. This explains why the EMC of the MF was reduced compared to the crosslinking. The remaining free volume of the resin can absorb water easier and requires higher EMC. The EMC of the crosslinked materials was very similar at $a_{\mathrm{w}}$ $>0.5$, which could mean that about $1 \%$ zinc chloride or less can give similar results with respect to generating dense regions (Figure 2). In the same figure, EMC was not significantly changed before 0.4 water activity, but at higher water activity, MF exhibited sharp increase in EMC, whereas gradual increase was observed for MF resin.

3.2. Modeling of Moisture Sorption Isotherms. The experimental moisture isotherms data were fitted to GAB and BET models at 25,40 , and $55^{\circ} \mathrm{C}$ using nonlinear regression analysis. The GAB and BET equation allow the determination of the monolayer moisture content $\left(m_{\mathrm{o}}\right)$, which is the measure of the expected sorption property of the material. Generally, the monolayer values calculated from GAB and BET (Tables 1 and 2) were influenced by the temperature and the level of zinc chloride $\left(\mathrm{ZnCl}_{2}\right)$. Sesame oil resin material exhibited higher $m_{\mathrm{o}}$ than cottonseed oil indicating more binding sites due to low crosslinking reaction efficiency (Table 1). Therefore, less binding sites were

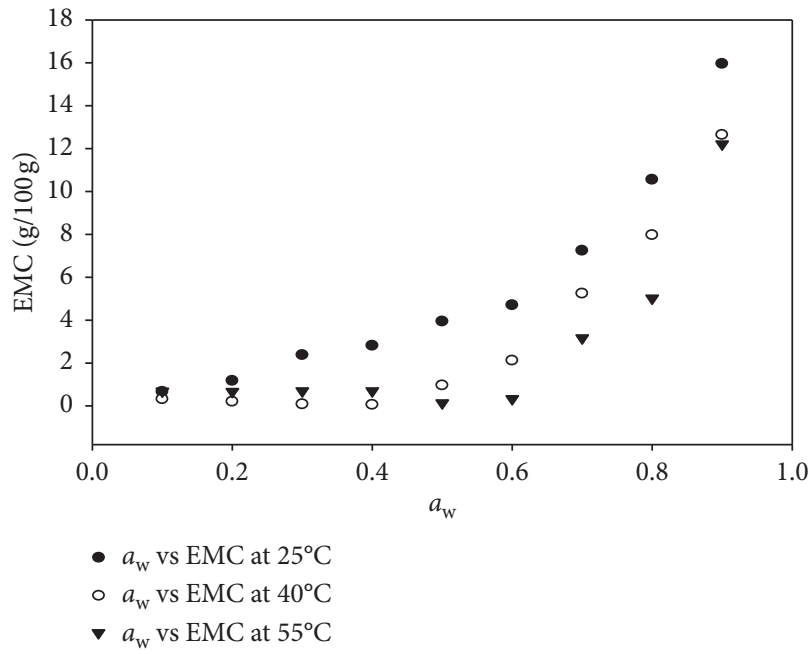

Figure 1: Adsorption EMC of pure MF at 25, 40, and $55^{\circ} \mathrm{C}$.

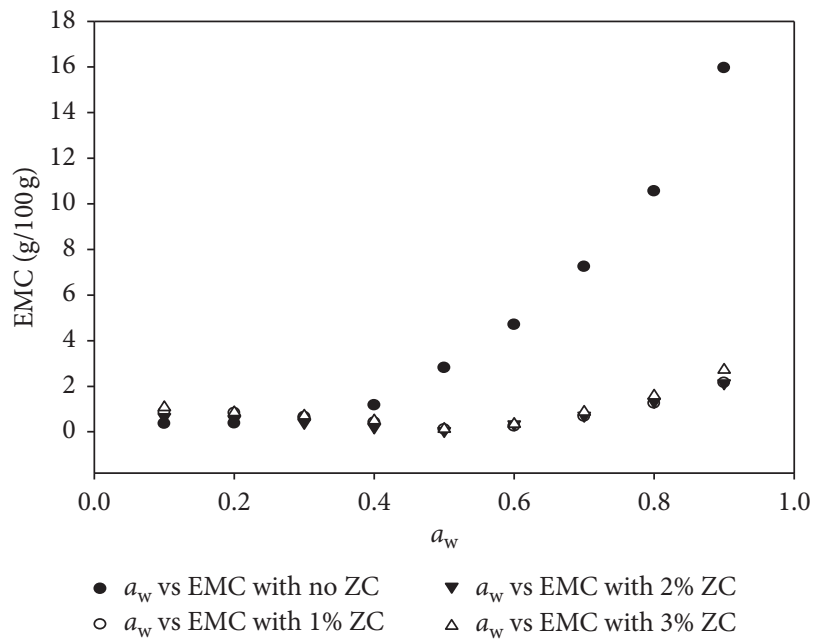

FIGURE 2: Adsorption of millet flour at $0,1,2$, and $3 \%$ zinc chloride at $25^{\circ} \mathrm{C}$.

TABLE 1: GAB and BET parameters for moisture sorption isotherms for millet flour/epoxidized sesame and cottonseed oil resins $\left(m_{\mathrm{o}} \mathrm{g} /\right.$ $100 \mathrm{~g}$ water dry basis).

\begin{tabular}{|c|c|c|c|c|c|c|c|}
\hline \multicolumn{8}{|c|}{ Epoxidized sesame oil resin } \\
\hline \multirow[t]{2}{*}{${ }^{\circ} \mathrm{C}$} & $\% \mathrm{ZnCl}_{2}$ & $T$ & C & $m_{\mathrm{o}}$ & K & $\begin{array}{l}\text { GAB } \\
\text { RMSE }\end{array}$ & $\begin{array}{c}\text { BET } \\
\text { RMSE }\end{array}$ \\
\hline & 0 & 4.0178 & 2.1428 & 3.3337 & 0.9013 & 0.876 & 3.320 \\
\hline \multirow{3}{*}{25} & 1 & 9.9862 & 8.8589 & 0.3947 & 0.9712 & 0.327 & 0.516 \\
\hline & 2 & 5.7577 & 4.4694 & 0.7413 & 0.9190 & 0.2779 & 0.935 \\
\hline & 3 & 13.8465 & 12.7614 & 0.4746 & 0.9780 & 0.472 & 0.518 \\
\hline \multirow{3}{*}{40} & 1 & 4.1559 & 2.4804 & 0.3068 & 0.9404 & 0.7639 & 0.5795 \\
\hline & 2 & 4.7685 & 3.3414 & 0.0571 & 0.9740 & 1.1004 & 1.0776 \\
\hline & 3 & 4.8698 & 3.4640 & 0.0849 & 0.9651 & 1.0366 & 1.0067 \\
\hline \multirow{3}{*}{55} & 1 & 4.9132 & 3.5157 & 0.0503 & 0.9716 & 1.1978 & 1.1791 \\
\hline & 2 & 4.7832 & 3.3594 & 0.0624 & 0.978 & 1.2873 & 1.2676 \\
\hline & 3 & 4.8306 & 3.4168 & 0.0345 & 0.9805 & 1.1455 & 1.1340 \\
\hline
\end{tabular}

$m_{\mathrm{o}}=$ monolayer moisture content; RMSE $=$ root-mean-square error; $C$ and $K$ are GAB parameters related to monolayer and multilayer properties. 
TABLE 2: GAB and BET parameters for moisture sorption isotherms for millet flour/epoxidized sesame and cottonseed oil resins $\left(m_{\mathrm{o}} \mathrm{g} /\right.$ $100 \mathrm{~g}$ water dry basis).

\begin{tabular}{|c|c|c|c|c|c|c|c|}
\hline \multicolumn{8}{|c|}{ Cottonseed oil resin } \\
\hline${ }^{\circ} \mathrm{C}$ & $\% \mathrm{ZnCl}_{2}$ & $T$ & C & $m_{\mathrm{o}}$ & $K$ & $\begin{array}{c}\text { GAB } \\
\text { RMSE }\end{array}$ & $\begin{array}{c}\text { BET } \\
\text { RMSE }\end{array}$ \\
\hline & 0 & 4.0178 & 2.1428 & 3.3337 & 0.9013 & 0.87 & 3.32 \\
\hline \multirow{3}{*}{25} & 1 & 4.9107 & 3.5127 & 0.0050 & 0.9858 & 2.40 & 2.39 \\
\hline & 2 & 4.0039 & 2.0648 & 0.3471 & 0.9928 & 0.39 & 1.00 \\
\hline & 3 & 4.0286 & 2.1841 & 0.1926 & 0.9888 & 1.05 & 0.83 \\
\hline \multirow{3}{*}{40} & 1 & 27.0162 & 25.976 & 0.1401 & 0.4996 & 2.70 & 1.77 \\
\hline & 2 & 4.4803 & 2.9736 & 0.1593 & 0.9365 & 0.58 & 0.56 \\
\hline & 3 & 4.0476 & 2.2432 & 0.5729 & 0.9349 & 0.20 & 2.14 \\
\hline \multirow{3}{*}{55} & 1 & 4.8855 & 3.4827 & 0.0238 & 0.9793 & 2.75 & 2.71 \\
\hline & 2 & 5.2513 & 3.9074 & 0.0051 & 0.9726 & 2.86 & 2.85 \\
\hline & 3 & 4.9279 & 3.5332 & 0.0348 & 0.9742 & 2.98 & 2.91 \\
\hline
\end{tabular}

$m_{\mathrm{o}}=$ moisture content; RMSE $=$ root-mean-square error; $C$ and $K$ are GAB parameters related to monolayer and multilayer properties.

available on the cottonseed resin which could be due to better crosslinking. This can be attributed to less unsaturated fatty acids of the sesame oil which generated limited number of oxirane rings during epoxydization. Epoxy resin crosslinking reaction is based on the amidolysis of oxirane rings. It was obvious that $m_{\mathrm{o}}$ has the tendency to decrease at higher temperatures due to the reduction in the number of the water-binding sites induced by temperature [35]. The prediction of $m_{\mathrm{o}}$ is critical because the water molecules below $m_{\mathrm{o}}$ water is strongly bound to the material and does not take part in any biochemical reactions. Therefore, this information is important for storage and the use of the resin material presented here, because the remaining nonprotein portion of the millet flour that did not participate in the crosslinking process could be available for moisture absorption, thus causing deterioration of the resin. After crosslinking epoxidized oil and proteins (epoxy ring and amide), the remaining ingredients of millet flour are rich in hydrophilic hydroxyl groups $(-\mathrm{OH})$. Within the same temperature, $m_{\mathrm{o}}$ values were lower at higher $\mathrm{ZnCl}_{2}$ except for the 2\% (Table 1). Since crosslinked materials are not homogeneous, this could cause variations in the size of the dense area with respect to the less dense area which has an adverse effect on $m_{\mathrm{o}}$. The constant $C$ is the total heat of sorption of the first layer of water vapor bound directly to the active binding sites, whereas $K$ represents the multilayer water molecules with respect to the bulk water rather than vapor. The $C$ value is always positive, and $K$ is less than unity. The values of $K$ and $C$ presented here showed that GAB and BET are suitable for fitting the millet epoxy resin data (Tables 1 and 2).

The goodness of fit of GAB and BET was determined by testing the percentage root-mean-square error, RMSE, against the experimental isotherm data [32]. The RSM of the $\mathrm{GAB}$ model for the sesame oil epoxy resin at $25^{\circ} \mathrm{C}$ ranged from 2.77 to 0.47 , at $40^{\circ} \mathrm{C}$ from 0.76 to 1.03 , and at $55^{\circ} \mathrm{C}$ from 1.14 to 1.28 , whereas BET exhibited similar RSM values compared to GAB as shown in Tables 1 and 2. Cottonseed oil resin exhibited RMSE values higher than sesame oil resin (Table 2) which could be due to the difference in the

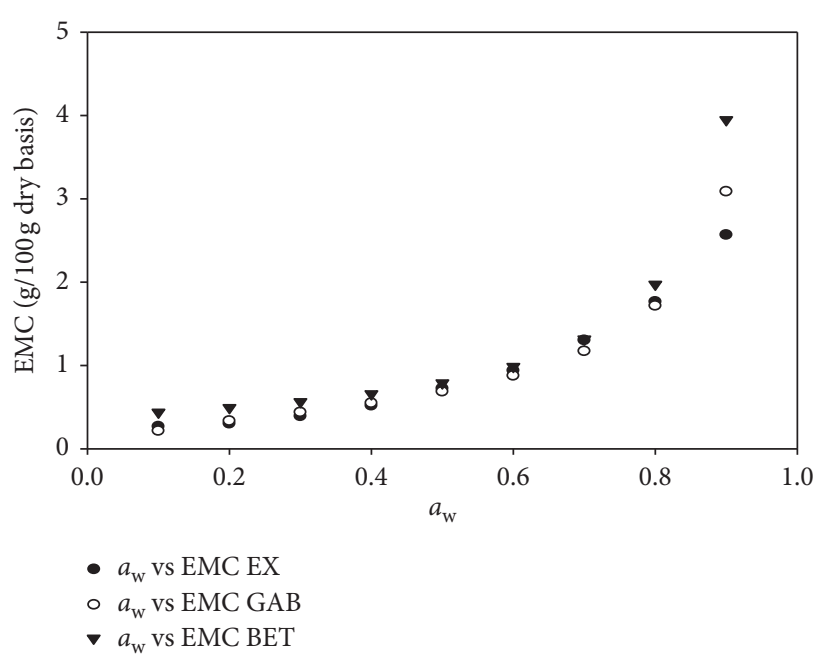

FIgUre 3: Comparison between experimental, GAB, and BET isotherms of millet flour resin $\left(2 \%\right.$ zinc chloride) at $25^{\circ} \mathrm{C}$.

crosslinking process discussed above. The two resins listed in Tables 1 and 2 showed differences in $C$ and $m_{\mathrm{o}}$ values which is reflected in the RMSE. Usually, low RSM values strengthen the usefulness of the GAB model for determining the water sorption isotherm of any material. Based on the data in Tables 1 and 2, the GAB and BET models can be used for predicting the EMC of sesame and cottonseed oil resins.

Comparisons between the experimental EMC, GAB, and BET isotherms are presented in Figures 3 and 4. In these figures, GAB appeared to have an extended range of application relative to BET, but both models give good fit at $a_{\mathrm{w}}$ $<0.6$ after which an upward swerve is observed. This sharp deviation indicates less water vapor is absorbed on the surface than that indicated by the models. This behavior is clear for the BET model especially at $40^{\circ} \mathrm{C}$ (Figure 4), but at $25^{\circ} \mathrm{C}$, both models showed sharp upward deflection after 0.7 $a_{\mathrm{w}}$ (Figure 3).

3.3. Isosteric Heat of Sorption (IHS). The IHS was calculated at several moisture contents ( $8-20 \%$ ) by plotting $\ln a_{\mathrm{w}}$ vs. 1/ $T$ using the data derived from the sorption isotherms (Figure 5). The slops of these lines were used for IHS $\left(q_{\mathrm{st}}\right)$ calculation. The maximum $q_{\text {st }}$ of millet flour resin was $21.94 \mathrm{~kJ} / \mathrm{mol}$ at $0.12 \mathrm{~g} / \mathrm{g}$ moisture content, and the minimum was $3.44 \mathrm{~kJ} / \mathrm{mol}$ at $0.75 \mathrm{~g} / \mathrm{g}$ moisture content (Figure 6). From the data presented here, it was shown that $q_{\mathrm{st}}$ decreases with increase in the amount of water absorbed, which is indicative of reduced water interaction, i.e., less binding energy (Figure 6). Therefore, the isosteric heat is intensely dependent on moisture content, where the energy necessary for sorption increases at low equilibrium moisture content. Similar effects were detected for nylon 6,10 water absorption and for several poly(alkyl-methacrylate) materials. Skirrow et al. $[35,36]$ described the similarity among heat of absorption of different systems which indicates that the interaction between water molecules and active binding sites of the absorbing surface will be alike. In this case, water is hydrogen bonded to the sorption sites. The prompt increase 


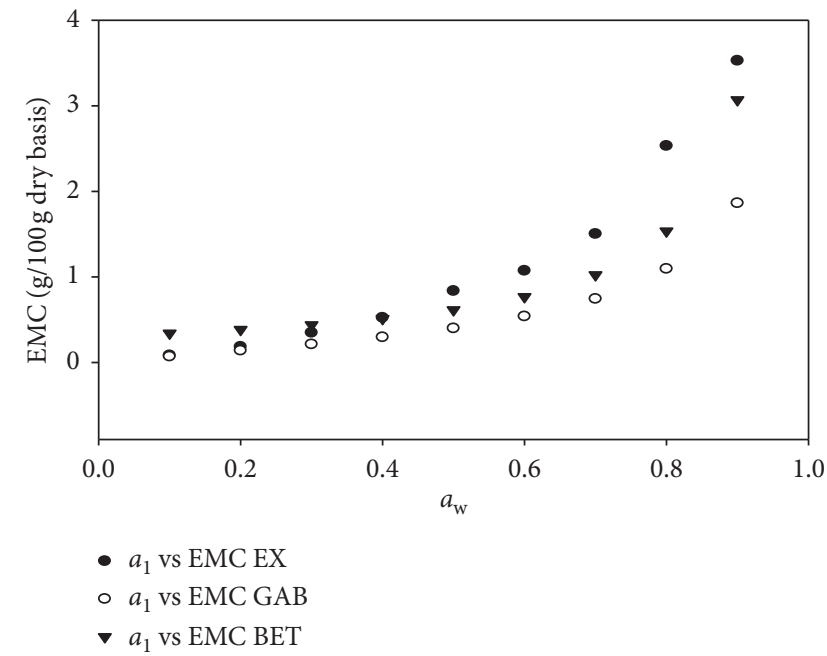

Figure 4: Comparison between experimental, GAB, and BET isotherms of millet flour resin ( $2 \%$ zinc chloride) at $40^{\circ} \mathrm{C}$.

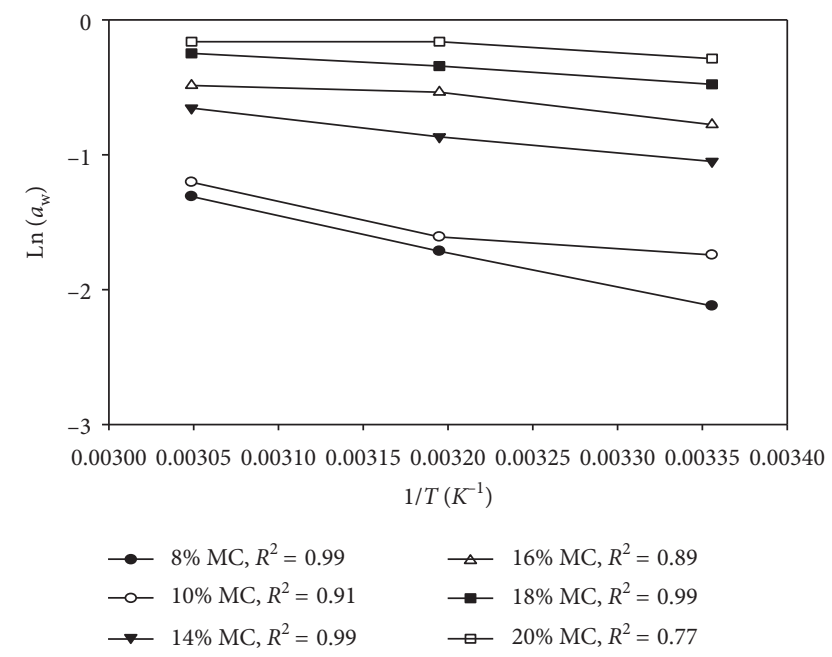

FIGURE 5: Isosteric heat of sorption $\operatorname{Ln} a_{\mathrm{w}}$ as a function of $1 / T\left(\mathrm{~K}^{-1}\right)$ for millet flour epoxy resin at constant moisture content.

in IHS at low moisture content is due to the presence of active binding sites on the surface of the material covered with water molecules forming monolayer. When these active sites are covered with monolayer water, they become less active producing lower heat of sorption [37].

\section{Conclusion}

Absorption isotherms of millet flour/epoxidized sesame or cottonseed oil exhibited sigmoidal shape, which is characterized as type II isotherm. The equilibrium moisture content (EMC) decreased with increase in temperature. The EMC of the resin showed slight change with increase in water activity, but for the millet flour, sharp increase after 0.4 $a_{\mathrm{w}}$ was observed. Millet flour presented lower EMC at higher water activity when compared to the resin. Zinc chloride did not significantly affect the isotherm profile. The RMSE values

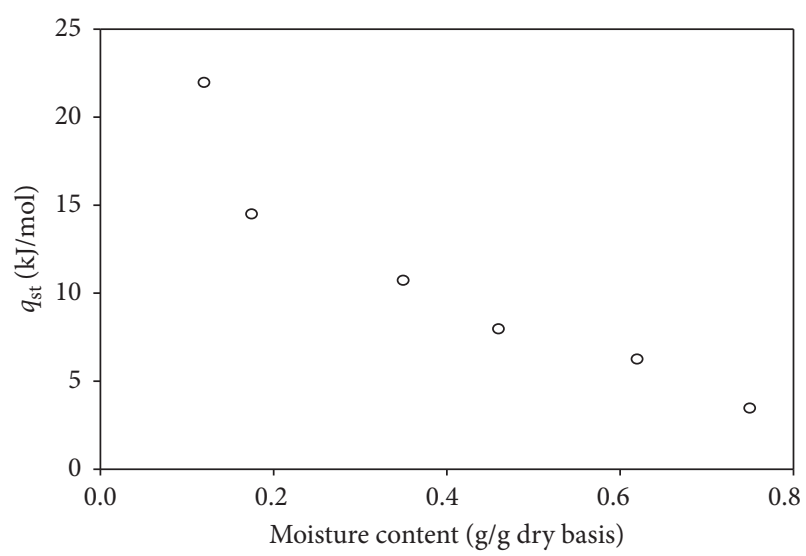

Figure 6: Isosteric heat of sorption $\left(q_{\mathrm{st}}\right)$ of millet flour as a function of moisture content.

indicated that GAB was more suitable to predict the isotherm at lower temperatures, while BET was appropriate at higher temperatures. The GAB appeared to have an extended range of application relative to BET, but both models give a good fit at $a_{\mathrm{w}}<0.6$ after which an upward swerve was observed. It is concluded that millet flour resin must be used below $60 \%$ relative humidity. The isosteric heat decreases with increase in the amount of water absorbed, whereas the energy necessary for sorption increases at low equilibrium moisture content.

\section{Data Availability}

The data used to support the findings of this article are available from the corresponding author upon request.

\section{Conflicts of Interest}

The authors declare that they have no conflicts of interest.

\section{Acknowledgments}

This project was funded by the National Plan for Science, Technology and Innovation (MAARIFAH) (Grant no. 11AGR-1602-02) and the King Abdulaziz City for Science and Technology, Kingdom of Saudi Arabia.

\section{References}

[1] H. Zhanga and G. Mittalb, "Biodegradable protein-based films from plant resources: a review," Environmental Progress and Sustainable Energy, vol. 29, no. 2, pp. 203-220, 2014.

[2] N. Reddy and Y. Yang, "Thermoplastic films from plant proteins," Journal of Applied Polymer Science, vol. 130, no. 2, pp. 729-738, 2013.

[3] C. E. Browning, "The mechanisms of elevated temperature property losses in high performance structural epoxy resin matrix materials after exposures to high humidity environments," Polymer Engineering and Science, vol. 18, no. 1, pp. 16-24, 1978.

[4] M. D. Garrison and B. G. Harvey, "Bio-based hydrophobic epoxy-amine networks derived from renewable terpenoids," Journal of Applied Polymer Science, vol. 133, no. 45, 2016. 
[5] M. Lettieri and M. Frigione, "Effects of humid environment on thermal and mechanical properties of a cold-curing structural epoxy adhesive," Construction and Building Materials, vol. 30, pp. 753-760, 2012.

[6] M. Fernández-García and M. Y. M. Chiang, "Effect of hygrothermal aging history on sorption process, swelling, and glass transition temperature in a particle-filled epoxy-based adhesive," Journal of Applied Polymer Science, vol. 84, no. 8, pp. 1581-1591, 2002.

[7] G. Z. Xiao and M. E. R. Shanahan, "Irreversible effects of hygrothermal aging on DGEBA/DDA epoxy resin," Journal of Applied Polymer Science, vol. 69, pp. 363-369, 1998.

[8] G. Mensitieri, M. Lavorgna, P. Musto, and G. Ragosta, "Water transport in densely crosslinked networks: a comparison between epoxy systems having different interactive characters," Polymer, vol. 47, no. 25, pp. 8326-8336, 2006.

[9] Y. Ngono, Y. Maréchal, and N. Mermilliod, "Epoxy-amine reticulates observed by infrared spectrometry. I: hydration process and interaction configurations of embedded $\mathrm{H} 2 \mathrm{O}$ molecules," Journal of Physical Chemistry B, vol. 103, no. 24, pp. 4979-4985, 1999.

[10] S. Cotugno, G. Mensitieri, P. Musto, and L. Sanguigno, "Molecular interactions in and transport properties of densely cross-linked networks: a time-resolved FT-IR spectroscopy investigation of the epoxy/H2O system," Macromolecules, vol. 38, no. 3, pp. 801-811, 2005.

[11] P. Musto, G. Ragosta, G. Scarinzi, and L. Mascia, "Probing the molecular interactions in the diffusion of water through epoxy and epoxy-bismaleimide networks," Journal of Polymer Science Part B: Polymer Physics, vol. 40, no. 10, pp. 922-938, 2002.

[12] J. Zhou and J. P. Lucas, "Hygrothermal effects of epoxy resin. Part I: the nature of water in epoxy," Polymer, vol. 40, no. 20, pp. 5505-5512, 1999.

[13] L. Barral, J. Cano, J. López, P. Nogueira, C. Ramirez, and M. J. Abad, "Water sorption in tetrafunctional phenol novalac epoxy mixtures cured with diamine," Journal of Thermal Analysis and Calorimetry, vol. 52, no. 3, pp. 823830, 1998.

[14] K. I. Ivanova, R. A. Pethrick, and S. Affrossman, "Investigation of hydrothermal ageing of a filled rubber toughened epoxy resin using dynamic mechanical thermal analysis and dielectric spectroscopy," Polymer, vol. 41, no. 18, pp. 6787-6796, 2000.

[15] C. Grave, I. McEwan, and R. A. Pethrick, "Influence of stoichiometric ratio on water absorption in epoxy resins," Journal of Applied Polymer Science, vol. 69, no. 12, pp. 2369-2376, 1998.

[16] J. W. Chin, T. Nguyen, and K. Aouadi, "Sorption and diffusion of water, salt water, and concrete pore solution in composite matrices," Journal of Applied Polymer Science, vol. 71, no. 3, pp. 483-492, 1999.

[17] Z. Ahmad, M. P. Ansell, and D. Smedley, "Effect of nano and micro-particle additions on moisture absorption in thixotropic room temperature cure epoxy-based adhesives for bonded-in timber connections," International Journal of Adhesion and Adhesives, vol. 30, no. 6, pp. 448-455, 2010.

[18] R. Leger, A. Roy, and J. C. Grandidier, "Non-classical water diffusion in an industrial adhesive," International Journal of Adhesion and Adhesives, vol. 30, no. 8, pp. 744-753, 2010.

[19] G. C. Papanicolaou, T. V. Kosmidou, A. S. Vatalis, and C. G. Delides, "Water absorption mechanism and some anomalous effects on the mechanical and viscoelastic behavior of epoxy system," Journal of Applied Polymer Science, vol. 99, no. 4, pp. 1328-1339, 2006.

[20] M. J. Adamson, "Thermal expansion and swelling of cured epoxy resin used in graphite/epoxy composite materials," Journal of Materials Science, vol. 15, no. 7, pp. 1736-1745, 1980.

[21] A. F. Abdelkader and J. R. White, "Water absorption in epoxy resins: the effects of the crosslinking agent and curing temperature," Journal of Applied Polymer Science, vol. 98, no. 6, pp. 2544-2549, 2005.

[22] A. A. Mohamed, S. Hussain, M. S. Alamri, M. A. Ibraheem, and A. A. Abdo Qasem, "Amidolysis of oxirane: effect of protein type, oils, and $\mathrm{ZnCl}_{2}$ on the rheological properties of cross-linked protein and oxirane," International Journal of Polymer Science, vol. 2018, Article ID 9670565, 11 pages, 2018.

[23] H. Lee and K. Neville, Handbook of Epoxy Resins, McGrawHill, New York, NY, USA, 1982.

[24] R. J. Morgan and E. T. Mones, "The cure reactions, network structure, and mechanical response of diaminodiphenyl sulfone-cured tetraglycidyl 4,4'diaminodiphenyl methane epoxies," Journal of Applied Polymer Science, vol. 33, no. 4, pp. 999-1020, 1987.

[25] L. Chiao and R. E. Lyon, "A fundamental approach to resin cure kinetics," Journal of Composite Materials, vol. 24, no. 7, pp. 739-752, 1990.

[26] C. Maggana and P. Pissis, "Water sorption and diffusion studies in epoxy resin system," Journal of Polymer Science Part B: Polymer Physics, vol. 37, no. 11, pp. 1165-1182, 1999.

[27] J. R. M. d'Almeida, N. Cella, S. N. Monteiro, and L. C. M. Miranda, "Thermal diffusivity of an epoxy system as a function of the hardener content," Journal of Applied Polymer Science, vol. 69, no. 7, pp. 1335-1341, 1998.

[28] J. Chirife, E. O. Timmermann, H. A. Iglesias, and R. Boquet, "Some features of the parameter k of the GAB equation as applied to sorption isotherms of selected food materials," Journal of Food Engineering, vol. 15, no. 1, pp. 75-80, 1992.

[29] E. Ayranci, "Equilibrium moisture characteristics of dried eggplant and okra," Food/Nahrung, vol. 39, no. 3, pp. 228-233, 1995.

[30] R. E. Harry-O'kuru and C. J. Carriere, "Synthesis, rheological characterization and constitutive modeling of polyhydroxy triglycerides of milkweed oil," Journal of Agricultural and Food Chemistry, vol. 50, no. 11, pp. 3214-3221, 2002.

[31] R. E. Harry-O’kuru, A. Mohamed, S. H. Gordon, and J. Xu, "Syntheses of novel protein products (milkglyde, saliglyde, and soyglyde) from vegetable epoxy oils and gliadin," Journal of Agricultural and Food Chemistry, vol. 60, no. 7, pp. 16881694, 2012.

[32] S. Kaya and T. Kahyaoglu, "Thermodynamic properties and sorption equilibrium of pestil (grape leather)," Journal of Food Engineering, vol. 71, no. 2, pp. 200-207, 2005.

[33] W. A. M. McMinn and T. R. A. Magee, "Thermodynamic properties of moisture sorption of potato," Journal of Food Engineering, vol. 60, no. 2, pp. 157-165, 2003.

[34] F. O. Ayorinde, B. D. Butler, and M. T. Clayton, "Vernonia galamensis: a rich source of epoxy acids," Journal of the American Oil Chemists' Society, vol. 67, no. 11, pp. 844-845, 1990.

[35] G. Skirrow and K. R. Young, "Sorption diffusion and conduction in polyamide penetrant," Polymer, vol. 15, no. 12, pp. 771-776, 1974. 
[36] E. Ayranci and O. Duman, "Moisture sorption isotherms of cowpea (Vigna unguiculata L Walp) and its protein isolate at 10, 20 and $30^{\circ} \mathrm{C}$," Journal of Food Engineering, vol. 61, pp. 297-307, 2004.

[37] F. Kaymak-Ertekin and A. Gedik, "Sorption isotherms and isosteric heat of sorption for grapes, apricots, apples and potatoes," LWT - Food Science and Technology, vol. 37, no. 4, pp. 429-438, 2004. 

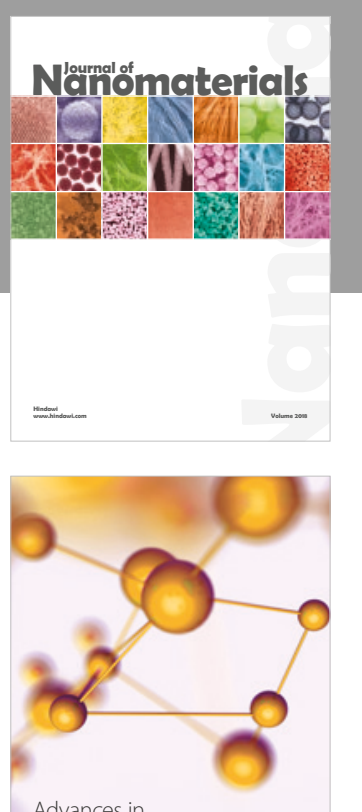

Physical Chemistry
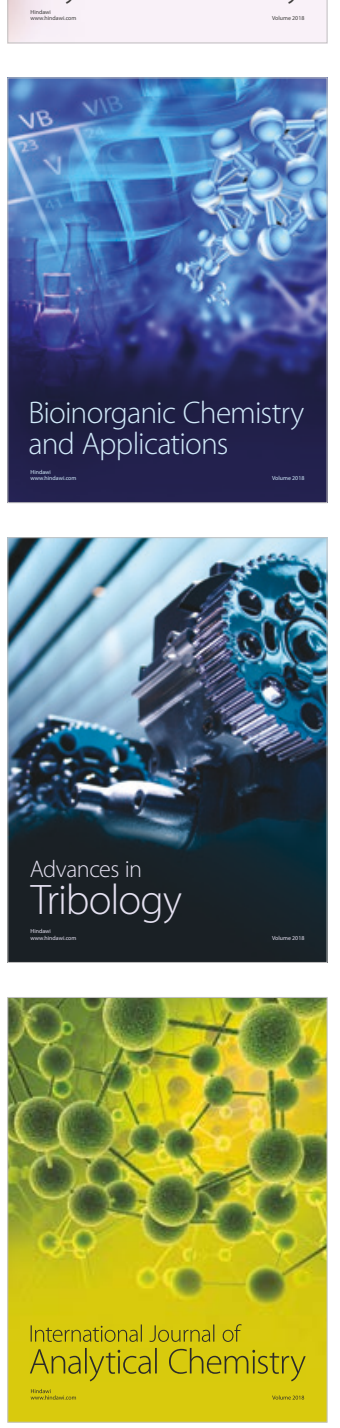

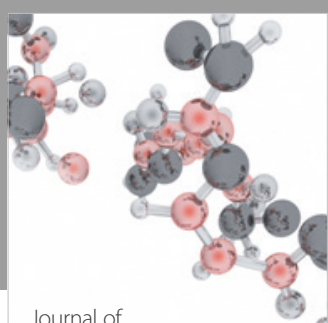

Analytical Methods

in Chemistry

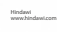

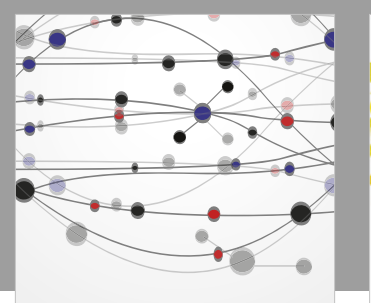

The Scientific World Journal

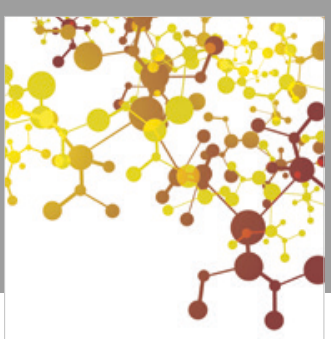

Journal of

Applied Chemistry
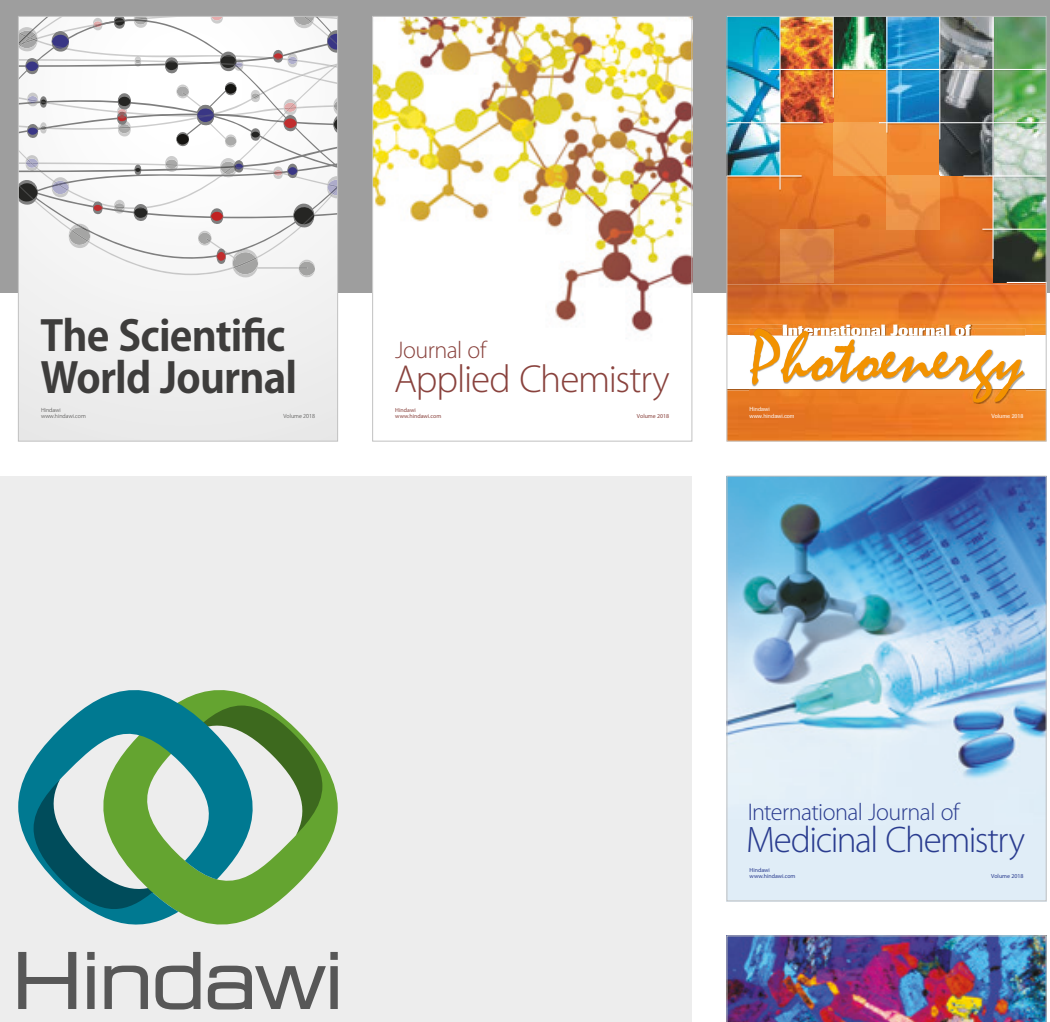

Submit your manuscripts at

www.hindawi.com
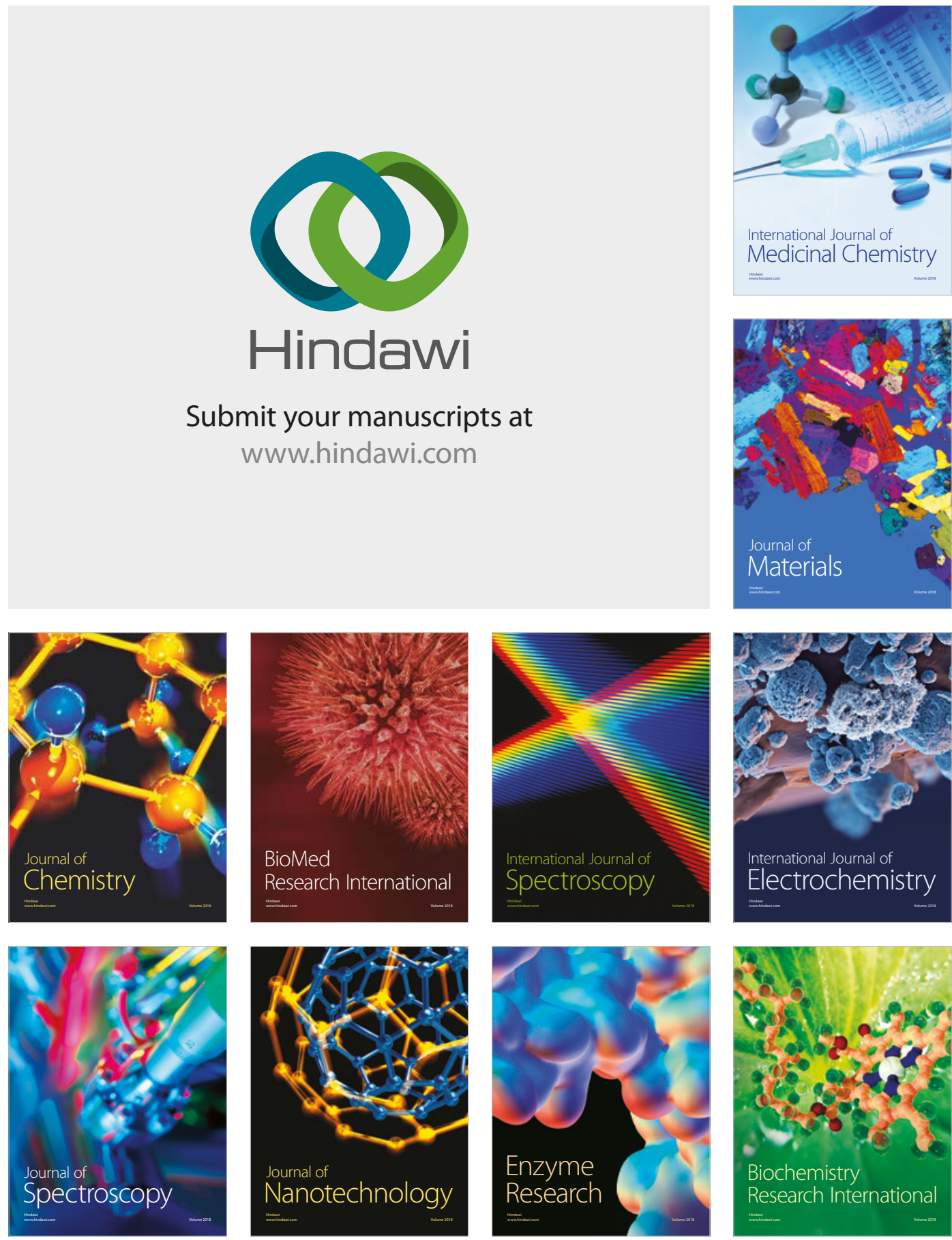
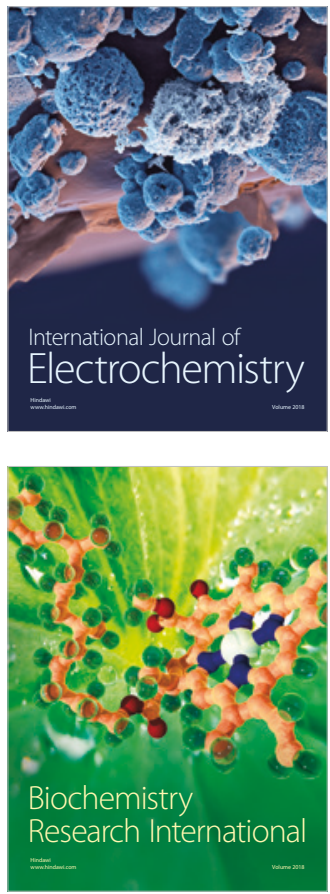